\title{
Anxiety of Accommodation: Kiao-Iology and Comparative Poetics
}

\author{
Wang Xiteng \\ School of Foreign Studies \\ Guangzhou University \\ Guangzhou, China \\ 784767600@qq.com
}

\begin{abstract}
Kiao-Iology is the theoretical production of the interactions of the great eastern and western theories and economic activities. Not only is it a response of the "anxiety of theory" in the domestic academic circles, but also a tremendous contribution of Chinese schools in the third stage of comparative literature. There are various similarities and differences between Kiao-Iology and comparative poetics, and this paper aims to explore their dialectical relationship by comparing their extension and connotations of the concept in order to rationalize the existence of Kiao-Iology in comparative literature, especially putting it into the reinterpretation of the western theoretical adaptations in order to vividly demonstrate the practice and impact of the theoretical interactions and integrations in modern China.
\end{abstract}

Keywords-Kiao-Iology; Comparative poetics; Globalization; Chinese schools; Anxiety of theory

\section{INTRODUCTION}

Derived from the "flexibility" and "transformation" concept, the I has profoundly affected the Chinese way of thinking. This way of thinking led to the change of the liberal arts and sciences in the process of Chinese modernization, and it also determined the theoretical anxiety and theoretical change in the construction and vocalization of the Chinese school of comparative literature. This article deliberately selected the word "transformation" to emphasize the first nature of "communicative" in comparative literature. It hopes to "open up" barriers to different regions, times, and disciplines from a more pluralistic perspective. The "Education of Overseas Chinese", which is emphatically discussed in the article, is the "opening up" tool produced in the context of "theory anxiety" of the Chinese school. It rationalizes it as the methodology of comparative literature (especially comparative poetics), and it is a search for more universality. The regular perspective of human poetics. Specific to the application of Kiao-Iology in comparative poetics, in terms of theoretical concepts, "Comparative Poetics" (especially "Comparative Chinese and Western Poetics") has the incommensurability of the concept of "Poetics" and "Theories can serve as a bridge to the ditch. In addition, the spatial characteristics (physics space, spiritual space and social space) emphasized by the Overseas Chinese School of Learning are more in line with current trends in the "space turn" of the academic world. They can be used as a supplement to comparative literature.

\section{II. "THEORY ANXIETY" OF THE CHINESE SCHOOL}

The introduction of western learning that descended in the late Ming and early Qing dynasty, especially the introduction of western literary theory since the May Fourth Movement, which witnessed the ups and downs of China's modernization. After the theoretical fever of the 1990s, the domestic academic circles began to look at western literary theory more cautiously and objectively. It is worth mentioning that this change of attitude from "hunger and thirst" to "change in power" has a close relationship with the Western literary theory with "post" as the prefix (post-structuralism, postmodernism). The literary theory trends of post-colonialism, etc.) emphasize the dissolution of the center and authority and call for the reconstruction of marginal and vulnerable subjects. Spivak is such a scholar, who demonstrated the progress of western society in the evolution of comparative literature. She not only noticed the decline of literary works as a product in the capital market in Western consumer society after the 1970s [1](PII) also creatively proposed the attributes of comparative literature "crossing boarders" [1](P2), rationalizing interdisciplinary propositions such as ethnic studies and regional studies into the field of comparative literature studies. In China, although the concept of "Chinese School" for comparative literature was proposed by $\mathrm{Li}$ Dasan, an American scholar, as early as 1977, it was not until the theoretical fever of the 1990s that the concept of "Chinese Comparative Literature" was widely accepted domestically. This opportunity was established on the basis of many scholars' refutation of Spivak's theory. The aphasia, alienation and marginalization caused by the long-term imbalance of theoretical exchanges have made the construction of the Chinese school a necessity, and rationalized it in theory. The landmark event was after Cao Shunqing had repeatedly discussed and repaired, in 2001 he officially named the development of comparative literature in China as the third stage of the development of comparative literature, clearly pointing out that the third stage of comparative literature is the most prominent. The characteristic is "cross-heterogeneous culture"[2]. Finally, in 2005, he proposed the "variation theory" of comparative literature, which emphasizes that "variation is a common fact in the process of communication 
between different literature and culture. More importantly, it is also the basic law for the exchange, integration and development of culture and civilization."[3]

It now appears that we are still in the second stage and the theoretical anxiety has not dissipated. One noteworthy phenomenon is that, with the revival of the "world literature" issue in recent years, Western scholars are also stopping their eyes on "testing, adjusting, amending, and expanding western terminology and theoretical models". The establishment of the Chinese school did not stem from the French school, while the American school emphasizes the subjectivity based on its own culture and the context of globalization. The reason for its "theory anxiety" is, on the one hand, the disequilibrium of discourse power in the process of the exchange of Chinese and Western poetics; on the other hand, there is no more theoretical concept of ontological significance for dialogue. When Zhao Xiaoqi talked about the problems in the domestic comparative poetics study, he pointed out that "in Chinese and Western poetics, there are many rich and complex ontological meanings" [4]. In the current relatively fixed poetics research mode, it is still in a shadow state. This shows that "theory anxiety" is closely related to the domestic scholars' practical concern and identity.

\section{CREATION OF THE CONCEPT OF KIAO-IOLOGY UNDER THE PERSPECTIVE OF COMPARATIVE POETICS}

Kiao-Iology is one of the outputs of the Chinese scholar Ye Jun in the context of "theory anxiety" of the Chinese school. In fact, the creation of the concept of overseas Chinese learning is itself a relatively poetic issue. In his systematic book "Changes and Inflections: The Concept of Overseas Chinese Learning", he introduces the origins, definitions, rules, and research objects of Kiao-Iology and emphasizes: "The historical process of modern China has been faltering and has broken its promise. Born to the grief of the vicissitudes of life... The whole country is all about 'innovation', but its vocabulary is over-inflicted, but it is another new word." [5] (P1) It refers to the fact that when Ye Jun studied how Goethe, Schiller and other European enlightenment thoughts realized the construction of the German national spirit, he involuntarily impinged upon the current situation of the Chinese intellectual world. For the German intellectual elite, since the Enlightenment, we have always faced a problem of selfidentification and national construction. This clue has been followed, but the question is how to achieve this goal. There are different explorations and considerable ambiguities in methods and means. The phenomena of intergenerational succession, teacher-student revolt, and friend-breaking robe... These phenomena that occur in intellectual elites are not for the sake of personal self-interest, but disputes among the larger ones concern the establishment of the spirit of the German nationality itself. [6]

The emergence of Kiao-Iology concept is consistent with the more essential nature of poetics on the basis of ontological significance than the current combination of Chinese and Western poetics. The so-called "everything in the yin and yang forces to promote changes in the contradictions, the process of change is through sympathy," those "Kyrgyzstan" are often sympathetic nature of the upper and lower ambiguity, and "fierce" is contrary. Therefore, the name of "Kiao-Iology" also includes the meaning of sympathy. In other words, in the process of indigenization, it naturally covers the meaning of interaction and achieves sympathetic effect. Therefore, I will change it again. It is easy to have three advances. One is variation, the other is transaction, and the other is simplicity. [5] (P4-5)

Kiao-Iology has the attributes of Western poetics. This has a close relationship with the theoretical background of western learning in the past two hundred years and Ye Hao's European tour. First of all, the study of overseas Chinese is compatible with the development and rush of western space theory since the $20^{\text {th }}$ century. Foucault once predicted: "The history of Western ideas before the $19^{\text {th }}$ century has been tangled with the theme of time. People are generally obsessed with history and focus on issues such as development, crisis, circulation, past, and death. The $20^{\text {th }}$ century heralded the arrival of a space age. The time we experience and feel may not be a material existence that has evolved from time to time in a traditional sense, but is more likely to be a network of different spaces that are intertwined and formed."[7] The change in consciousness is fundamentally related to the fact that frequent economic and cultural exchanges have made people's spatial awareness unprecedentedly strengthened. Overseas Chinese learners focus on the analysis of the migration of a person, thing, or concept in the physical space. They also pay attention to the differences in their spiritual space before and after the Kiao-Iology, and always place all these analyses in the context of social space. Ye Jun also has a similar expression: "The Kiao-Iology phenomenon is neither a simple displacement phenomenon but a combination of a material phenomenon and a spiritual phenomenon." [5] (P89) From an internal point of view, this shift of reality will lead to the change of individual spirit. However, he has always realized that "the structural difference between Western binary opposition thinking and China's interdependent thinking" [8] has not been misunderstood in terms of cognitive judgments, and it has clearly adopted the "change" of the "Book of Changes".

Second, there is also a clear link between the overseas unlearned theory and psychoanalytic theory of unconsciousness. In the process of realizing Kiao-Iology in specific literary works or theorists, it is easy to reveal the "political unconsciousness" or "cultural unconsciousness" that Jameson said about his ideology. This point is fully reflected in Ye Jun's analysis of Said's "concept of overseas Chinese" [9]. When talking about "Orientalism," Said confessed: "Because "Orientalism" really used Raymond's work very much, or I always tried to understand a sentence in Raymond's work. "[10] In the face of heterogeneous cultures, self-identity or unconsciousness (or ideology) has become more apparent. However, it is precisely because of the many shifts in the realities of space that Sadat made him look more calmly and objectively at the issue of self-identity and the development of his own cultural tradition. 


\section{APPLICATION AND PROSPECT OF OVERSEAS CHINESE I-} CHING STUDIES

Does Yi Jun learn to overlap with comparative literature, comparative poetics, and even Chinese and Western comparative literature and art? Scholar Zhou Yunlong pointed out in the book review of "Changes and Inflections: The Idea of Overseas Chinese Learning", pointing out that the concept of "Kiao-Iology" continued the thought lineage of the Chinese School of Comparative Literature. [11] It is worth mentioning that after Ye Jun published his book "Changes and Inflections: The Idea of Overseas Chinese Learning" (January 2014), which introduced methodological issues such as the concepts, connotations, extensions, and rules of overseas Chinese studies. The new book "Literature, Comparison, Overseas Chinese" (October 2014) was published as part of the Academic Library of Comparative Literature and World Literature. And he also admitted in the book's postscript: "Although it cannot be regarded as a strictly professional background of comparative literature, in fact, my interest in comparative literature is indeed quite strong." [12] talks about Kiao-Iology and others. When the disciplines are related, Ye Jun hopes that Yi Kiao-Iology can "provide another way of thinking and exploring that is conducive to observing all things in the world and approaching the truth. If you want to achieve this, you must fully realize that you are learning from various disciplines." [13] (P229) eventually reached "within the subject, but also outside the academic" [5] (P102). The author believes that the origin of this idea is closely related to the multidisciplinary characteristics of Kiao-Iology's own school. Therefore, the application and forward-looking research of overseas Chinese Yi Xue (易学) in other disciplines are particularly necessary. Overseas Chinese Yi Xue is still in its infancy, and its development in several disciplines focusing on comparative literature is just around the corner. On the analysis of the influence of overseas Chinese Yi studies and comparative literature, Zeng Yanbing is currently a representative of this field. He pointed out: "Easy Chinese studies are very close to the comparative study of comparative literature, but it is more flexible, changeable, and broader than impact studies." [14] In addition, Lu Yi also studied the relationship between Yi and the Yi Jing of Yiyi and Yiyi, and pointed out the relationship between it and the comparative literature. He pointed out: "Yi Jian," and "Yi Jian" and "Yi Yi" in "One Easy and Three Meanings". The idea of 'and 'not easy' runs through Chinese comparative literature scholars' thinking about the 'comparability' of comparative literature, 'comparative practice, discipline theory, and 'leaving' and many other issues." [15] In fact, the author mentions that the application of Kiao-Iology in the field of comparative poetics will have broad and far-reaching prospects. One of them is the phenomenological interpretation of Chinese and Western literary theories, especially the literary and cultural innovations resulting from the exchange of literary and artistic theories of "the East Learning from the West" and "Western Learning from the East".

First of all, because of the obvious incommensurability of the concept of "poetics" in "comparative poetics" (especially the "Chinese and Western Comparative Poetics"), Kiao-Iology can be used as a new interpretation perspective (or methodology) as a trench. Cross-cultural poetics bridge. If China does not have "poetics" as a cultural tradition referred to by the West, then this concept is worth further research in China's overseas Chinese, especially since the 1990s, the concept of "poetics" has evolved. Why is "Chinese and Western Comparative Literature and Art" rather than "Chinese-Western Comparative Poetics"? What is the difference between the two? The so-called "Poetics" does not only refer to the narrow sense of knowledge related to "poetry", but also refers to the general term of all internal theories of literature. However, it is worth noting that, from the perspective of cultural generation, "poetics" is disseminated as a Western cultural product, and after mingling with Chinese literary theory, it will inevitably mutate. Therefore, "Poetics" has allegations in the discourses of both Chinese and Western scholars, and it is even harder to communicate. It can be said that "comparative poetics" is not a comparison of "poetics" because the concept of "poetics" is absent or mutated in China. This point is mentioned in $\mathrm{Yu}$ Hong's book "Chinese Literary Theory and Western Poetics": The phrase "comparative poetics" comes not only from the West but also from the "Western." When Westerners initially used this claim in Western cultural circles to refer to poetic comparisons between Western countries, there was nothing wrong with it, because both French poetry and English poetry were "poetics." Although they differ, they are just differences within the same system. However, when some people use this term for the comparative study of the spiritual legacy of the Western and non-Western cultural circles, the legitimacy of this practice is highly questionable because there is nothing in the non-Western cultural circle."[16] Therefore, Rao Pengzi, Jiang Shuzhuo, Yu Hong and other scholars advocate the use of "Chinese and Western Comparative Literature and Art" to replace "Chinese and Western Comparative Poetics" proposed by Huang Yaomian and Tong Qingbing. This argument still needs further discussion, but from the basic concept, China's "Poetics" and Western "Poetics" do indeed grow in different cultural soils. In the hundreds of years of Western learning, Western poetry The dissemination and acceptance of learning in China and its influence on the concept of China's current "poetics" need more explanation. As far as the current academic situation is concerned, the concept of "poetics" in the West is at the core of absoluteness. The Chinese traditional "poetics" is more of a state of marginalized aphasia.

Second, Kiao-Iology has considerable vitality in the study of the "overseas learning in the West" and the "advancement of Western learning" in the interaction between Chinese and Western literature. The "triad" mentioned here is the "moderate mean", or more specifically placed in the current context is "the world". The long-standing theoretical anxiety of the Chinese school has a close relationship with the cultural influence caused by the strong western economy, especially the "gradual learning of western culture" from the liberation period and the reform and opening up to the present. At the same time, however, we should proceed from the overall history and view the overall interaction between the "Introduction of Eastern Learning in the West" and the "Introduction of Western Learning to the East" from the yin and yang theory of the Book of Changes. In other words, we cannot ignore how "Eastern Learning is getting to the West" 
(as the representative of our ancient theory "voice") is how to make things easier in the Western world. Having the overall consciousness of history and actively seeking theoretical innovations and exchanges can better rejuvenate the Chinese culture. As Lu Xun emphasized, Chinese culture should "beyond the trend of thought in the world. "[17]

Third, the study of overseas Chinese Yi Xue in translation poetics also needs further development. This point needs special emphasis on the differences between the "translated learning" and the "translated" of the specific literary works and theories in the process of "advancement of learning in the east" and "advancement of learning in the west". After all, in the process of translation, there is inevitably the existence of signifiers and implied inequalities, and the resulting untranslatability. Then the difference in translation (or even if there is no difference), after entering the new cultural context and being accepted (that is, the process of "overseas Chinese"), the "easy" place and its consequences will be misunderstood. Reading and innovative theoretical concepts and imagination. The influence of the translation and dissemination of "The Good and Bad Weather" in Europe on Goethe's "world literature" imagination is a typical case. The "Chinese Wicker Chair" [18] brings to Goethe the individual pleasure of the stranger's imagination. The image of the "cane chair" is from China to Germany's "Chinese Overseas Chinese", especially in Goethe. In the individual's spiritual space, different images form an imaginary community that transcends national boundaries and nations: world literature. It is worth mentioning that the concept of world literature is not the first of Goethe's creation. Herder had already mentioned it in the "Encouragement of Humanitarian Letters" published in 1793. The motive is that the cultural products of oriental literature in the West are still Dede's concretization: "Now our history of European literature is too narrow. It has missed many wonderful artistic treasures of the world. It's a pity. It's a pity! We should rule out the limitations of narrow nationalities and the peoples of the world." The establishment of a free exchange of spiritual merchandise encompasses all the most precious works created by various nationalities at all stages of historical development, all of which are included in our own components, making our literary history a worldwide allembracing literary history. The establishment of the free exchange of spiritual goods has included the world's most precious works in its own parts. It is a kind of "world literature" consciousness that is very strong but very strong and distinct.

\section{CONCLUSION}

In the era of "theory anxiety", "change" is not easy, but it is even harder to "pass through" the barriers between Chinese and Western studies and disciplines. However, if we look at the long-term construction of the Chinese School of Comparative Literature, such innovative theories as the "Easy Chinese" learn from the Chinese and Western theoretical traditions based on the actual needs to generate the innovative theory that conforms to the human cognition and development law should be more beneficial! And in the generation of this theory, comparative poetics has an irreplaceable role. Facts have proved that in the process of achieving the ultimate Utopia of world literature, comparative poetics will surely demonstrate the value of its new theory of creation.

\section{REFERENCES}

[1] G. Spivak. The Death of a Subject [M]. Beijing: Peking University Press, 2014

[2] Huang Weiliang, Cao Shunqing. The Extension of the Disciplinary Theory of Chinese Comparative Literature: Selected Papers of Taiwan Scholars [C]. Beijing: Peking University Press, 1998. 139-143.

[3] Shunqing, Cao. The Variation Theory of Comparative Literature. Berlin: Springer[M]. 2013.

[4] Zhao Xiaoqi. Problems in the Study of Comparative Poetics in China [J]. Review of Century Literature, 2008(1): 20.

[5] Ye Jun. Change and Inflection: The Idea of Overseas Chinese Learning [M]. Beijing: Peking University Press, 2014.

[6] Ye Jun. The Spiritual Worries of the Times [M]. Beijing: Peking University Press, 2010: 12.

[7] Bao Yaming. City and Culture (Part 1). Politics of Postmodernity and Geography [C]. Shanghai: Shanghai Education Press, 2001. 18-28.

[8] Tian Chenshan. Chinese Dialectics: From the Book of Changes to Marxism [M]. Beijing: China Renmin University Press, 2008. Preamble: 14.

[9] Ye Jun. "Theoretical travel" or "Confucianism abroad" - discussion centering on Said and Lukács, edited by Ye Xie. Qiao Yi’s first series [C]. Beijing: Social science literature Press, 2014. 258-279.

[10] Raymond Williams, Edward Said. Media, Marginality and Modernity, Raymond Williams. Modernist Politics - Opposition to the New State Church [M]. Yan Jiayi, Beijing: Commercial Press, 2002. 256-257.

[11] Edward Said. Incompatibility - Memoir of Said [M]. Translation by Peng Huaidong. Shanghai: Sanlian Bookstore, 2004. 4.

[12] Zhou Yunlong. The Extension of Comparative Literature Methodology and the Reconstruction of Chinese Academic Subjectivity [J]. Chinese Comparative Literature, 2016(2):214.

[13] Ye Z. The concept of the overseas Chinese phenomenon and its connotation and extension[J]. Journal of Shanghai Normal University (Philosophy and Social Sciences Edition), 2013(1):36.

[14] Zeng Yanbing. Overseas Chinese Yi Xue and Comparative Literature [J] Guangdong Social Sciences, 2016(1):147.

[15] Lu Xin. A Look at the 30-year Development of the Chinese School of Comparative Literature from the Perspective of "One Transmutation and Three Implications"[J]. Journal of Shenzhen University(Humanities and Social Sciences), 2016(3): 132.

[16] Yu Hong. Chinese Literary Theory and Western Poetics [M]. Shanghai: Sanlian Bookstore, 1999: 4.

[17] Lu Xun. Complete Works of Lu Xun (Volume One) [C]. Beijing: People's Publishing House, 2005: 57

[18] Aikman. Goethe's Conversation [M]. Translated by Zhu Guangshun, Beijing: People's Publishing House, 1982: 112. 